University of Wollongong

Research Online

Australian Institute for Innovative Materials -

Papers

Australian Institute for Innovative Materials

$1-1-2014$

\title{
Enhanced electrochemical properties of cobalt doped manganese dioxide
} nanowires

Byoung Chul Kim

Korea Basic Science Institute

C Justin Raj

Dongguk University

W J. Cho

Dongguk University

W G. Lee

Dongguk University

Hyeon Taek Jeong

University of Wollongong, hj632@uowmail.edu.au

See next page for additional authors

Follow this and additional works at: https://ro.uow.edu.au/aiimpapers

Part of the Engineering Commons, and the Physical Sciences and Mathematics Commons

Research Online is the open access institutional repository for the University of Wollongong. For further information contact the UOW Library: research-pubs@uow.edu.au 


\title{
Enhanced electrochemical properties of cobalt doped manganese dioxide nanowires
}

\begin{abstract}
The various molar concentrations of cobalt doped manganese dioxide (Co-MnO2) nanostructures were synthesized by an hydrothermal technique for electrochemical supercapacitor application. The X-ray diffraction analysis showed that the samples were composed of multiphase of $\mathrm{MnO} 2$ with dominant reflections of $\mathrm{Y}-\mathrm{MnO} 2$ structure of crystallization. The morphological studies displayed the existence of MnO 2 nanowires with the width of $10-20 \mathrm{~nm}$ and showing a good degree of crystallization. The electrochemical characterization was performed using cyclic voltammetry, galvanostatic charge/ discharge test and impedance spectroscopy in $1 \mathrm{M} \mathrm{Na} 2 \mathrm{SO} 4$ aqueous electrolyte. All the samples exhibit a typical ideal capacitive behavior with an increasing order of specific capacitance values with respect to the increase in the concentration of cobalt ions up to a certain limit. The specific capacitance of $415 \mathrm{~F} \mathrm{~g}-1$ was delivered by $5 \%$ Co-MnO2 sample at $0.2 \mathrm{~A} \mathrm{~g}-1$ which was nearly double that of bare $\mathrm{MnO} 2$ electrode of $231 \mathrm{~F} \mathrm{~g}-1$. Moreover, the Co-MnO2 electrode shows an excellent capacitance retention $(97.3 \%)$ after 5000 charge and discharge cycles.
\end{abstract}

\section{Keywords}

electrochemical, properties, enhanced, nanowires, cobalt, dioxide, manganese, doped

Disciplines

Engineering | Physical Sciences and Mathematics

\section{Publication Details}

Kim, B., Justin Raj, C., Cho, W., Lee, W., Jeong, H. \& Yu, K. Hyun. (2014). Enhanced electrochemical properties of cobalt doped manganese dioxide nanowires. Journal of Alloys and Compounds, 617 491-497.

\section{Authors}

Byoung Chul Kim, C Justin Raj, W J. Cho, W G. Lee, Hyeon Taek Jeong, and K H. Yu 


\title{
Enhanced electrochemical properties of cobalt doped manganese dioxide nanowires
}

\author{
Byung Chul Kim ${ }^{\mathrm{a}}$, C. Justin Raj ${ }^{\mathrm{a}}$, Won-Je Cho ${ }^{\mathrm{a}}$, Won-Gil Lee ${ }^{\mathrm{a}}$, Hyeon Taek Jeong ${ }^{\mathrm{b}}$, Kook \\ Hyun $\mathrm{Yu}^{\mathrm{a}}{ }^{*}$
}

${ }^{a}$ Department of Chemistry, Dongguk University-Seoul, Seoul-100-715, Republic of Korea

${ }^{b}$ ARC Centre of Excellence for Electromaterials Science, IPRI, AIIM Facility, Innovation Campus, University of Wollongong, NSW 2522, Australia.

* Corresponding author. Tel.: +82 22260 3709; Fax: +82 222688204

E-mail: yukook@dongguk.edu (K. H. Yu)

\begin{abstract}
The various molar concentrations of cobalt doped manganese dioxide $\left(\mathrm{Co}-\mathrm{MnO}_{2}\right)$ nanostructures were synthesized by an hydrothermal technique for electrochemical supercapacitor application. The X-ray diffraction analysis showed that the samples were composed of multiphase of $\mathrm{MnO}_{2}$ with dominant reflections of $\gamma-\mathrm{MnO}_{2}$ structure of crystallization. The morphological studies displayed the existence of $\mathrm{MnO}_{2}$ nanowires with the width of 10-20 nm and showing a good degree of crystallization. The electrochemical characterization was performed using cyclic voltammetry, galvanostatic charge/discharge test and impedance spectroscopy in $1 \mathrm{M} \mathrm{Na}_{2} \mathrm{SO}_{4}$ aqueous electrolyte. All the samples exhibit a typical ideal capacitive behavior with an increasing order of specific capacitance values with respect to the increase in the concentration of cobalt ions up to a certain limit. The specific capacitance of $415 \mathrm{Fg}^{-1}$ was delivered by $5 \% \mathrm{Co}-\mathrm{MnO}_{2}$ sample at $0.2 \mathrm{Ag}^{-1}$ which was nearly double that of bare $\mathrm{MnO}_{2}$ electrode of $231 \mathrm{Fg}^{-1}$. Moreover,
\end{abstract}


the Co- $\mathrm{MnO}_{2}$ electrode shows an excellent capacitance retention (97.3\%) after 5000 charge and discharge cycles.

Keywords: Electrode materials; Energy storage materials; Nanostructured materials; Electrochemical impedance spectroscopy; Oxide materials

\section{Introduction}

Supercapacitors (SCs) are excellent power sources for electronic devices and automotive application due to their high power density, better energy density and durability[1]. Based on the charge storage mechanism, the SCs have been classified into two categories; one as electrochemical double layer capacitors (EDLCs) that use double-layer capacitance arising from the separation of charge at the interface between the solid electrode/electrolyte, and the other as pseudocapacitors which utilize fast faradaic redox reactions that occur near the electrode surface or takes place inside the bulk of the materials [2, 3]. In recent years the pseudocapacitance materials like metal oxides, sulfides, hydrides and conducting polymers received considerable attention in energy storage applications [4-10]. The large specific capacitances and high energy density of these materials can meet the demand of high power and energy density in modern devices than that of carbon based electric double-layer capacitors. The metal oxides such as $\mathrm{RuO}_{2}, \mathrm{NiO}, \mathrm{Co}_{3} \mathrm{O}_{4}, \mathrm{MnO}_{2}$ etc., have been considered as better candidates for pseudocapacitance electrode materials[11-14]. Among these $\mathrm{MnO}_{2}$ is of particular interest due to its low cost, low toxicity, high theoretical capacitance, and excellent capacitive performance in aqueous electrolytes, which adds more potential towards supercapacitor electrodes [15-17]. The charge storage mechanism of $\mathrm{MnO}_{2}$ is based on fast faradaic redox reactions either that occur near the 
electrode surface or takes place inside the bulk of the materials over an appropriate range of potentials [18-20]. In order to achieve high capacitive performance, a large surface area and a fast ion/electron transport by the electrode material are required.

Generally, $\mathrm{MnO}_{2}$ was the most studied material due to its promising electrochemical properties; but its specific capacitance values are still far below the theoretical value. The poor electronic conductivity and limited surface area are responsible for low specific capacitance values in $\mathrm{MnO}_{2}$ based SCs [21, 22]. Several attempts have been made to improve the capacitive performance of $\mathrm{MnO}_{2}$ by the addition of conductive additives like carbon nanotubes, polymers, graphene and other composites to enhance the electron transport properties to attain a reasonable capacitance value [23-27]. Moreover, various transition metal oxides such as $\mathrm{Ni}, \mathrm{Pb}$, Mo and $\mathrm{V}$ oxides [28-31] that have been incorporated with $\mathrm{MnO}_{2}$ show considerable improvement in the specific capacitance and overall performance of the SCs. Cobalt oxide is another excellent material for supercapacitor electrode, whereby addition of cobalt ions to $\mathrm{MnO}_{2}$ shows a reasonable improvement in pseudocapacitive performances [32, 33]. Pramod [34] et. al., reported the doping of $\mathrm{Co}$ ions into the layered alkali $\mathrm{MnO}_{2}$ that showed a considerable improvement in the conductivity of the electrodes, and following this work a series of reports have been published on Co- $\mathrm{MnO}_{2}$ showing it to be a promising supercapacitor electrode material[35, 36].

Apart from the conductivity and transport properties, the specific capacitance mainly depends upon the surface area of the materials. Various morphological structures of $\mathrm{MnO}_{2}$ including nanorods, nanowires, nanosheets, nanoflakes, and nanoflowers[37-40] have been synthesized and effectively studied for their electrochemical performance. Mostly an hydrothermal method was adopted for the synthesis of the above mentioned $\mathrm{MnO}_{2}$ nanostructures. In general, the hydrothermal technique is a simple and effective green synthesis 
technique to fabricate nanomateriasl with different morphologies by optimizing the reaction temperature, time, $\mathrm{pH}$ and the active fill level or solvent used in the reaction. Large surface area nanostructures can be effectively synthesized on a large scale using this simple solution based hydrothermal technique [41, 42]. In this work we report the hydrothermal synthesis of Co- $\mathrm{MnO}_{2}$ nanocomposites for electrochemical supercapacitor. Cobalt of various molar percentage $(1,2,5$, $10 \%$ ) were incorporated in $\mathrm{MnO}_{2}$ and their electrochemical properties were studied extensively using cyclic voltammetry, galvanostatic charge/discharge tests and electrochemical impedance spectroscopy. Furthermore, the structural and morphology of synthesized nanoparticles were characterized by XRD, SEM, TEM, EDAX, and their surface area and pore size distributions were analyzed using a nitrogen physisorption technique.

\section{Experimental Methods}

\subsection{Synthesis of Co doped $\mathrm{MnO}_{2}$ nanomaterial}

Manganese(II) sulfate pentahydrate $\left(\mathrm{MnSO}_{4} \cdot 5 \mathrm{H}_{2} \mathrm{O}\right)$, Cobalt (II) sulfate heptahydrate $\left(\mathrm{CoSO}_{4} \cdot 7 \mathrm{H}_{2} \mathrm{O}\right)$ and Potassium persulfate $\left(\mathrm{K}_{2} \mathrm{~S}_{2} \mathrm{O}_{8}\right)$ were used as precursors for the hydrothermal synthesis of $\mathrm{MnO}_{2}$ and $\mathrm{Co}-\mathrm{MnO}_{2}$ nanocomposites. The process was begun by dissolving $\mathrm{MnSO}_{4}$. $5 \mathrm{H}_{2} \mathrm{O}(5 \mathrm{mM}), \mathrm{K}_{2} \mathrm{~S}_{2} \mathrm{O}_{8}(5 \mathrm{mM})$ and required mol percentage of $\mathrm{CoSO}_{4} 7 \mathrm{H}_{2} \mathrm{O}(0,1,2,5,10$ mol\%) into $75 \mathrm{~mL}$ of double distilled water under vigorous stirring at room temperature until the formation of an homogeneous solution. Finally, the mixture was transferred into a $100 \mathrm{~mL}$ Teflon-lined stainless autoclave and maintained at $160{ }^{\circ} \mathrm{C}$ for $3 \mathrm{~h}$ in a hot air oven. Then the autoclave was cooled naturally to room temperature. The obtained precipitate was washed several times in double-distilled water by repeated centrifugation and ultrasonication. Finally, the product was dried in oven at $80^{\circ} \mathrm{C}$ for $12 \mathrm{~h}$ and used for further characterization. 


\subsection{Characterization}

The crystalline structure of the synthesized samples were identified by using GBC MMA $\mathrm{XRD}$ (Australia) with $\mathrm{Cu} \mathrm{K \alpha}$ radiation $(\lambda=1.540598 \AA)$ operated at $30 \mathrm{kV}$ and $20 \mathrm{~mA}$ in the $2 \theta$ range $20^{\circ}-80^{\circ}$. Morphologies were characterized by field emission scanning electron microscope (JEOL-7500FA field emission SEM (Japan)). Transmission electron microscopy (TEM) images and EDS measurements were performed using a JEOL (Japan) model JEM-2100F at an accelerating voltage of $200 \mathrm{kV}$. The nitrogen absorption/desorption measurement was carried out using a Quantachrome surface analyzer at $77.35{ }^{\circ} \mathrm{C}$ employing the volumetric method. The specific surface area was calculated by the Brunauer-Emmett-Teller (BET) technique. The pore size distribution was estimated from the desorption branch of the isotherm by the Barrett-JoynerHalenda (BJH) method.

\subsection{Electrode fabrication and electrochemical measurements}

The bare and $\mathrm{Co}-\mathrm{MnO}_{2}$ electrodes were fabricated by mixing the active materials (70 wt\%), acetylene black (20 wt\%) and polyvinylidene fluoride (PVDF, $10 \mathrm{wt} \%$ ) in N-methyl-2pyrrolidone (NMP). The obtained paste was coated over a stainless steel substrate of exposed geometric area $1 \mathrm{~cm}^{2}$ and dried at $100{ }^{\circ} \mathrm{C}$ for $12 \mathrm{~h}$ in a vacuum oven. The mass of the active material present in the electrodes was determined to be $\sim 0.6 \mathrm{mg}$. Electrochemical studies such as cyclic voltammetry, galvanostatic charge/discharge and impedance measurements were performed at room temperature $\left(\sim 20^{\circ} \mathrm{C}\right)$ using ZIVE - SP2 (Korea) electrochemical workstation in a three electrode arrangement, including a working electrode of bare or Co- $\mathrm{MnO}_{2}$ electrodes, a platinum sheet counter electrode and a $\mathrm{Ag} / \mathrm{AgCl}$ reference electrode in $1 \mathrm{M} \mathrm{Na}_{2} \mathrm{SO}_{4}$ aqueous 
electrolyte. The electrochemical impedance spectra (EIS) of the electrodes were measured in the frequency range of $0.01 \mathrm{~Hz}-100 \mathrm{kHz}$ at an equilibrium open circuit potential $0 \mathrm{~V}$ with an AC perturbation of $5 \mathrm{mV}$ in $1 \mathrm{M} \mathrm{Na}_{2} \mathrm{SO}_{4}$ electrolyte.

\section{Results and Discussion}

\subsection{Structural analysis}

Fig. 1 shows the XRD patterns of the bare $\mathrm{MnO}_{2}$ and 1, 2, 5, $10 \mathrm{~mol} \%$ of $\mathrm{Co}-\mathrm{MnO}_{2}$ samples. All the samples show the same trend of diffraction pattern with multiple crystalline phases with a dominant diffractions of $\gamma$ type $\mathrm{MnO}_{2}$ phase. The corresponding strong peaks of each sample can be indexed as the orthorhombic phase of $\gamma-\mathrm{MnO}_{2}$ (JCPDS 44-0140). Moreover, the broad diffraction peaks at $\sim 18^{\circ}$ and $50^{\circ}$ correspond to the peaks of tetragonal phase of $\alpha$ $\mathrm{MnO}_{2}$ (JCPDS 44-0140). The formation of this type of $\alpha \cdot \gamma-\mathrm{MnO}_{2}$ mixed phase has been reported by Hill et. al.[43]. Apart from this, a few more diffraction peaks were observed nearly at 28.5, 37 and 65 which can be clearly identified as the K-birnessite type of layer structured $\mathrm{MnO}_{2}$ phase (JCPDS 80-1098). Rapid hydrothermal growth of $\mathrm{MnO}_{2}$ using the same combination of $\mathrm{MnSO}_{4}$. $5 \mathrm{H}_{2} \mathrm{O}$ and $\mathrm{K}_{2} \mathrm{~S}_{2} \mathrm{O}_{8}$ [39] at the same reaction temperature shows formation of pure K-birnessite phase of $\mathrm{MnO}_{2}$. But in our case the mixed phase of $\mathrm{MnO}_{2}$ nanostructure was formed by the same mixture and reaction temperature. This phase transformation might be due to long duration hydrothermal reaction than the reported reaction time (30 min); since a duration dependent hydrothermal reaction can easily affect the $\mathrm{MnO}_{2}$ phase of crystallization or transfer to other phases as reported by Wang and Li [44]. Even though no additional peaks related to the Co oxide 
phase appeared, in the $\mathrm{Co}-\mathrm{MnO}_{2}$ sample the intensity of peak at $18^{\circ}$ shows improvement with respect to the increase in concentration of Co doping; especially higher for $10 \% \mathrm{Co}-\mathrm{MnO}_{2}$ sample. This might be due to the presence for $\mathrm{Co}(\mathrm{OH})_{2}$, since the peak corresponds to the (001) diffraction of $\mathrm{Co}(\mathrm{OH})_{2}$; similar to that observed in bare Co sample prepared by this same route.

\subsection{Morphological and surface area analysis}

Fig. 2 a, b and c, d show the different magnification SEM images of bare and 5\% Co$\mathrm{MnO}_{2}$ samples. From these images, both the samples show the morphology of agglomerated microsphere with diameter ranges from 1 to $3 \mu \mathrm{m}$. At a high magnification, it can be observed that the $\mathrm{MnO}_{2}$ microspheres are composed of a large number of tiny nanowires in the order of a few nanometers. The TEM images (Fig. 3 a, b, c and d) further reveal that each $\mathrm{MnO}_{2}$ microspheres is made up of $\mathrm{MnO}_{2}$ nanowires with diameterr ranging from 5 to $20 \mathrm{~nm}$ and a length of about a few micrometers. The high resolution TEM image (Fig. 3 b) of $\mathrm{MnO}_{2}$ nanowires shows clear lattice fringes of the nanowires thus confirming the well crystalline nature of the nanowires. The TEM image of the $5 \% \mathrm{Co}-\mathrm{MnO}_{2}$ sample has some agglomeration of short nanorods with the nanowires, which might be due to the presence of some impurity phase due to cobalt ions. In addition, the HRTEM image (Fig. 3 d) shows high crystallinity of the short nanorods over the surface of $\mathrm{MnO}_{2}$ nanowires. The EDS analysis of the samples shown in Fig. 4 $\mathrm{a}$ and $\mathrm{b}$ clearly indicates the composition and the incorporation of Co ions in $\mathrm{MnO}_{2}$ nanostructure. Additionally a small amount of the $\mathrm{K}^{+}$is present in both the samples. Based on the $\mathrm{XRD}$ results, the presence of $\mathrm{K}$ ions can be concluded to be due to the existence of K-birnessite type of $\mathrm{MnO}_{2}$ structure in the synthesized samples. 
The specific surface area and pore size distribution of the $\mathrm{MnO}_{2}$ and $5 \% \mathrm{Co}-\mathrm{MnO}_{2}$ nanocomposite were obtained from an analysis of the desorption branch of $\mathrm{N}_{2}$ gas isotherms method. Fig. 5 shows that the isotherms are typical for a slightly mesoporous material with a small hysteresis loop at high partial pressures. The BET surface area and corresponding pore volume of the samples were calculated to be $42.25 \mathrm{~m}^{2} \mathrm{~g}^{-1}$ and $0.258 \mathrm{~m}^{3} \mathrm{~g}^{-1}$ for bare $\mathrm{MnO}_{2}$, and $44.96 \mathrm{~m}^{2} \mathrm{~g}^{-1}$ and $0.295 \mathrm{~m}^{3} \mathrm{~g}^{-1}$ for $5 \% \mathrm{Co}-\mathrm{MnO}_{2}$ sample respectively. As shown by BJH analysis (inset in Fig. 5), both the samples have a narrow pore size distribution of around $3.7 \mathrm{~nm}$. From this analysis, no considerable change in the surface area and pore size of $\mathrm{MnO}_{2}$ samples due to the presence of cobalt ions is observed. The slight enhancement in the surface area of the Co$\mathrm{MnO}_{2}$ sample may be due to the influence of the impurities observed in the TEM images.

\subsection{Cyclic voltammetry studies}

The cyclic voltammograms (CV) of the $\mathrm{MnO}_{2}$ and $\mathrm{Co}-\mathrm{MnO}_{2}$ electrodes measured in $1 \mathrm{M}$ $\mathrm{Na}_{2} \mathrm{SO}_{4}$ electrolyte at scan rates of $10 \mathrm{mVs}^{-1}$ are shown in Fig. 6. From the CV curves all the electrodes shows typical rectangular shapes, revealing the surface Faradaic reaction of the synthesized samples; that is, the surface electrosorption of $\mathrm{Na}^{+}$cations and the fast reversible successive surface redox reactions of the electrode by means of interaction/extraction processes of the proton according to Equation $(3.1)[3,45]$ :

$\left(\mathrm{MnO}_{2}\right)_{\text {surface }}+\mathrm{Na}^{+}+\mathrm{e}^{-} \leftrightarrow(\mathrm{MnOONa})_{\text {surface }}$

Moreover, no characteristic redox peaks were observed in all electrodes; indicating that the electrode is charged and discharged at a pseudo-constant rate over the complete voltammetric cycle. The specific capacitances $\left(\mathrm{C}_{\mathrm{sp}}, \mathrm{Fg}^{-1}\right)$ were calculated from the $\mathrm{CV}$ curve according to Eq. (3.2): 
$\mathrm{C}_{\mathrm{sp}}=\frac{\int \mathrm{idV}}{\mathrm{m} \times \mathrm{s} \times \Delta \mathrm{V}}$

where, $m$ is the mass of active material on electrodes (g), $s$ is the potential scan rate $\left(\mathrm{mVs}^{-1}\right), i$ is the voltammetric current (A), and $\Delta V$ is the potential window of $\mathrm{CV}$ curve. The estimated specific capacitance of the bare and 1, 2, 5, $10 \mathrm{~mol} \%$ of Co- $\mathrm{MnO}_{2}$ at the scan rate of $10 \mathrm{mVs}^{-1}$ are 143, 180, 206, 302 and $234 \mathrm{Fg}^{-1}$ respectively. The obtained values and the improved background current of the CV curves confirm the positive influence of Co ions in the supercapacitive performance of the $\mathrm{MnO}_{2}$ nanostructure. The $5 \% \mathrm{Co}-\mathrm{MnO}_{2}$ electrode exhibits the maximum specific capacitance value which is double that of the bare $\mathrm{MnO}_{2}$ electrode. But 10 $\% \mathrm{Co}-\mathrm{MnO}_{2}$ shows a decline in the capacitance value which reveals that Co ions doping have a positive effect up to a certain limit within the $\mathrm{MnO}_{2}$ nanocomposite. Moreover the bare $\mathrm{MnO}_{2}$ electrode exhibits higher specific capacitance value than that of $\gamma-\mathrm{MnO}_{2}$ of nearly the same surface area and morphology $[3,46]$. This might be attributed to the existence of other two highly electrochemical active systems of $\mathrm{MnO}_{2}$ like $\mathrm{K}$-birnessite and $\alpha-\mathrm{MnO}_{2}$ in the samples. Although these materials having low surface area, they can exhibit relatively high specific capacitances owing to their special type of layered structure with appropriate hydrate content and their promising Faradaic behavior[46, 47].

\subsection{Galvanostatic charge/discharge measurements}

The galvanostatic charge/discharge is an effective measurement technique to study more about the charge storage properties and stability of the electrodes. Fig.7 shows the charge/discharge profile of $\mathrm{MnO}_{2}$ and various concentrations of Co- $\mathrm{MnO}_{2}$ electrodes at $0.2 \mathrm{Ag}^{-1}$ of constant discharge current density. All the electrodes show a linear variation of the potential during both the charging and discharging processes; with nearly triangular shape representing 
excellent supercapacitor behavior. The specific capacitance $\left(C_{s p}\right)$ of the electrodes measured by the galvanostatic discharge process can be calculated using Equation (3.3):

$\mathrm{C}_{\mathrm{sp}}=\frac{\mathrm{I} \times \Delta \mathrm{t}}{\Delta \mathrm{V} \times \mathrm{m}}$

where $I$ is the constant discharge current (A), $\Delta t$ is the discharge time (s), $\Delta V$ is the potential window $(\mathrm{V})$, and $m(\mathrm{~g})$ is the mass of the active material in the electrode. According to this equation, the specific capacitance (SC) of the $\mathrm{MnO}_{2}$ and various concentration of Co- $\mathrm{MnO}_{2}$ at the constant current density of $0.2 \mathrm{~A} \mathrm{~g}^{-1}$ are 231 (bare), 292 (1\%), 325 (2\%), 415 (5\%) and $375 \mathrm{~F}$ $\mathrm{g}^{-1}(10 \%)$. From these values, it can be observed that the variation of $C_{s p}$ values are nearly consistent with those obtained from the CV measurements. It is clear that all the Co- $\mathrm{MnO}_{2}$ electrodes provide improved specific capacitances than that of bare $\mathrm{MnO}_{2}$, which may reflect an improved electrical conductivity caused by the incorporation of Co into the $\mathrm{MnO}_{2}$ nanostructures[34, 48]. Even though $10 \%$ Co- $\mathrm{MnO}_{2}$ shows better capacitance than bare $\mathrm{MnO}_{2}$ electrode, the value is less compared to the $5 \% \mathrm{Co}-\mathrm{MnO}_{2}$ electrode. This drop in $C_{s p}$ value confirms that the Co ions can improve the specific capacitance $\mathrm{MnO}_{2}$ up to a certain concentration of dopant $[36,48]$. This depicts some constraints in the pesudocapacitance reaction of the electrode with excess $\mathrm{Co}$ ions in $\mathrm{Na}_{2} \mathrm{SO}_{4}$ electrolyte. Since, generally, cobalt based electrodes have a narrow operational potential window and require a basic electrolyte $\mathrm{KOH}$ or $\mathrm{NaOH}$ ) for supercapacitor applications compared with the $\mathrm{MnO}_{2}$ based electrode materials, this might be the reason for the decrease in specific capacitance values in the case of higher concentrations of Co ions in $\mathrm{MnO}_{2}$ electrode. Fig. 8a represents the relationship between the specific capacitance and current densities; all the electrodes show decay of $C_{s p}$ with respect to the increase in current density. The drop in specific capacitance with increase in current densities is due to the less involvement of the active materials, whereas at low current densities the current 
accumulation process is slow and all the active materials sites and pores are involved in the energy storage process $[5,39]$. The cyclic stability of the $\mathrm{MnO}_{2}$ and $5 \%$ Co- $\mathrm{MnO}_{2}$ electrodes was also investigated by continuous charge/discharge measurements over 5000 cycles (Fig. 8b) at a constant current density of $5 \mathrm{Ag}^{-1}$. The $5 \% \mathrm{Co}-\mathrm{MnO}_{2}$ electrode has superior cycling stability with $97.3 \%$ retention of initial specific capacitance after 5000 cycles, which is higher than the cyclic stability of bare $\mathrm{MnO}_{2}$ electrode (92.8\%). The better performance and stability of the $5 \%$ Co- $\mathrm{MnO}_{2}$ electrode could be due to the Co species facilitating the electronic conduction within the metal oxide [11, 48].

\subsection{Impedance spectroscopy}

EIS analysis was performed for the electrodes to study the effect of Co species on the internal resistance, charge transfer and electrochemical kinetics of the electrodes. The obtained Nyquist plot for the $\mathrm{MnO}_{2}$ and Co- $\mathrm{MnO}_{2}$ electrodes are shown in Fig. 9a. Nyquist plots are composed of a spike in the low frequency region and an incomplete semicircle (inset of Fig. 9a) in the high frequency region indicating a pronounced capacitive behavior with a moderate resistance. The impedance spectra were analyzed by Zview software on the basis of the electrical equivalent circuit, as shown in the inset of Fig. 9a. The bulk solution resistance is represented as $R_{s}$, the double layer capacitance $\left(C P E_{d l}\right)$ and charge transfer resistance $\left(R_{c t}\right)$ across the electrode/electrolyte interface. The spike at lower frequency of the plots exhibits an angle between $45^{\circ}$ to $90^{\circ}$ relative to the real axis representing the diffusion control process of the electrode and it was fitted with an Warburg element $Z_{w}$. Additional RC components $R_{L}$ and $C_{p}$ were added to the circuit which represents the leakage resistance and pseudocapacitance of the electrodes. The fitting parameters of the electrodes are listed in Table 1. The overall resistance 
values of the electrodes are the combination of $R_{s}$ with $R_{c t}$ values[49], which were found to decrease with increase in Co content in the electrodes and confirming the influence of Co ion in the improvement of conductivity of the electrode. The leakage resistance $R_{L}$ is found to be larger for all the electrodes, indicating the negligible self-discharging property of the fabricated electrodes[50]. The low frequency pseudocapacitances $\left(C_{p}\right)$ of the electrodes are similar to those values obtained from the CV measurements, which shows the reliability of the fitted values. In addition to this, the Bode plots ( Fig. 9b) for $\mathrm{MnO}_{2}$ and $\mathrm{Co}-\mathrm{MnO}_{2}$ electrodes were obtained from the change of phase angle degree with respect to the different frequencies from $10 \mathrm{mHz}$ to 100 $\mathrm{kHz}$. The phase angle degree of the $\mathrm{MnO}_{2}$ electrodes with different concentration of Co species remained close to $90^{\circ}$ even in the higher frequency range, indicating better capacitive behavior of the electrodes.

\section{Conclusion}

Cobalt doped $\mathrm{MnO}_{2}$ nanocomposites were successfully synthesized by an hydrothermal method and used in the fabrication of supercapacitor electrodes. The $\mathrm{MnO}_{2}$ electrodes exhibit highly reversible charge/discharge features with an excellent specific capacitance due to the presence of various electrochemically active phases of $\mathrm{MnO}_{2}$ nanocrystals. Moreover, these experimental evidences confirm that the incorporation of certain amounts of Co ions in the $\mathrm{MnO}_{2}$ sites strongly influence the properties of the electrode by increasing the conductivity and electrochemical properties of the electrode. Among the various concentrations of Co dopant added, the $5 \mathrm{~mol} \%$ of Co doped $\mathrm{MnO}_{2}$ electrode shows a very high specific capacitance (415 Fg-

${ }^{1}$ ) at constant discharge current density of $0.2 \mathrm{Ag}^{-1}$ and a superior cycling stability (97.3 \%) over 5000 cycles. From this overall observation, the optimized hydrothermal growth condition and an 
appropriate amount of $\mathrm{Co}$ ions in the $\mathrm{MnO}_{2}$ nanocomposite affords an excellent electrode material for supercapacitor applications.

\section{Acknowledgements}

The authors would like to acknowledge authorities of Dongguk University-Seoul for their moral and financial support.

\section{References}

[1] B. Andrew, Ultracapacitors: why, how, and where is the technology, J. Power Sources 91 (2000) 37-50.

[2] R. Kotz, M. Carlen, Principles and applications of electrochemical capacitors, Electrochim. Acta 45 (2000) 2483-2498.

[3] W. Wei, X. Cui, W. Chen, D.G. Ivey, Manganese oxide-based materials as electrochemical supercapacitor electrodes, Chem. Soc. Rev. 40 (2011) 1697-1721.

[4] S. Patrice, G. Yury, Materials for electrochemical capacitors, Nat. Mater. 7 (2008) 845-854.

[5] M. Huang, Y. Zhang, F. Li, L. Zhang, Z. Wen, Q. Liu, Facile synthesis of hierarchical Co3O4@MnO2 core-shell arrays on Ni foam for asymmetric supercapacitors, J. Power Sources 252 (2014) 98-106.

[6] C.J. Raj, B.C. Kim, W.J. Cho, W.G. Lee, Y. Seo, K.H. Yu, Electrochemical capacitor behavior of copper sulfide (CuS) nanoplatelets, J. Alloys Compd. 586 (2014) 191-196.

[7] B. Qu, Y. Chen, M. Zhang, L. Hu, D. Lei, B. Lu, Q. Li, Y. Wang, L. Chen, T. Wang, betaCobalt sulfide nanoparticles decorated graphene composite electrodes for high capacity and power supercapacitors, Nanoscale 4 (2012) 7810-7816. 
[8] H. Chen, L. Hu, M. Chen, Y. Yan, L. Wu, Nickel-Cobalt Layered Double Hydroxide Nanosheets for High-performance Supercapacitor Electrode Materials, Adv. Fun. Mater. 24 (2014) 934-942.

[9] R. Andy, D. John, R. Ian, G. Shimshon, F. John P., Conducting polymers as active materials in electrochemical capacitors, J. Power Sources 47 (1994) 89-107.

[10] L. Zhang, G. Zhao, Y. Wang, Polyaniline nanowire electrodes with high capacitance synthesized by a simple approach, Mater. Sci. Eng., C 33 (2013) 209-212.

[11] B.C. Kim, G.G. Wallace, Y.I. Yoon, J.M. Ko, C.O. Too, Capacitive properties of RuO2 and Ru-Co mixed oxide deposited on single-walled carbon nanotubes for high-performance supercapacitors, Synt Met. 159 (2009) 1389-1392.

[12] L. Gu, Y. Wang, R. Lu, L. Guan, X. Peng, J. Sha, Anodic electrodeposition of a porous nickel oxide-hydroxide film on passivated nickel foam for supercapacitors, J. Mater. Chem., A 2 (2014) 7161.

[13] H. Xia, D. Zhu, Z. Luo, Y. Yu, X. Shi, G. Yuan, J. Xie, Hierarchically structured Co(3)O(4)@Pt@MnO(2) nanowire arrays for high-performance supercapacitors, Sci. Rep. 3 (2013) 2978.

[14] H. Jiang, T. Sun, C. Li, J. Ma, Hierarchical porous nanostructures assembled from ultrathin MnO2 nanoflakes with enhanced supercapacitive performances, J. Mater. Chem. 22 (2012) 2751.

[15] M. Huang, Y. Zhang, F. Li, L. Zhang, R.S. Ruoff, Z. Wen, Q. Liu, Self-Assembly of Mesoporous Nanotubes Assembled from Interwoven Ultrathin Birnessite-type $\mathrm{MnO} 2$ Nanosheets for Asymmetric Supercapacitors, Sci. Rep. 4 (2014).

[16] T. Mathieu, B. Thierry, B.l. Daniel, Influence of Microstucture on the Charge Storage Properties of Chemically Synthesized Manganese Dioxide, Chem. Mater. 14 ( 2002) 3946-3952. 
[17] H.Y. Lee, J.B. Goodenough, Supercapacitor Behavior with KCl Electrolyte, J. Solid State Chem. 144 (1999) 220-223.

[18] T. Mathieu, B. Thierry, B. Daniel, Charge Storage Mechanism of MnO2 Electrode Used in Aqueous Electrochemical Capacitor, Chem. Mater. 16 (2004) 3184-3190.

[19] N. Nagarajan, H. Humadi, I. Zhitomirsky, Cathodic electrodeposition of MnOx films for electrochemical supercapacitors, Electrochim. Acta 51 (2006) 3039-3045.

[20] R.N. Reddy, R.G. Reddy, Synthesis and electrochemical characterization of amorphous MnO2 electrochemical capacitor electrode material, J. Power Sources 132 (2004) 315-320.

[21] A.E. Fischer, K.A. Pettigrew, D.R. Rolison, R.M. Stroud, J.W. Long, Incorporation of Homogeneous, Nanoscale $\mathrm{MnO} 2$ within Ultraporous Carbon Structures via Self-Limiting Electroless Deposition: Implications for Electrochemical Capacitors, Nano Lett. 7 (2007) 281286.

[22] H. Huang, X. Wang, Graphene nanoplate-MnO2 composites for supercapacitors: a controllable oxidation approach, Nanoscale 3 (2011) 3185-3191.

[23] S.-L. Chou, J.-Z. Wang, S.-Y. Chew, H.-K. Liu, S.-X. Dou, Electrodeposition of MnO2 nanowires on carbon nanotube paper as free-standing, flexible electrode for supercapacitors, Electrochem. Commun. 10 (2008) 1724-1727.

[24] G. Xiong, K.P.S.S. Hembram, R.G. Reifenberger, T.S. Fisher, MnO2-coated graphitic petals for supercapacitor electrodes, J. Power Sources, 227 (2013) 254-259.

[25] W. Zhong-Shuai, R. Wencai, W. Da-Wei, L. Feng, L. Bilu, C. Hui-Ming, High-Energy MnO2 Nanowire/Graphene and Graphene Asymmetric Electrochemical Capacitors, ACS Nano, 4 (2010) 5835-5842. 
[26] C. Sheng, Z. Junwu, W. Xiaodong, H. Qiaofeng, W. Xin, Graphene OxideMnO2 Nanocomposites for Supercapacitors, ACS Nano, 4 (2010) 2822-2830.

[27] J.-G. Wang, Y. Yang, Z.-H. Huang, F. Kang, Rational synthesis of MnO2/conducting polypyrrole@carbon nanofiber triaxial nano-cables for high-performance supercapacitors, J. Mater. Chem. 22 (2012) 16943.

[28] M. Nakayama, A. Tanaka, S. Konishi, K. Ogura, Effects of heat-treatment on the spectroscopic and electrochemical properties of a mixed manganese/vanadium oxide film prepared by electrodeposition, J. Mater. Res. 19 (2011) 1509-1515.

[29] N. Masaharu, T. Akihiro, S. Yoshimine, T. Tsuyoshi, O. Kotaro, Electrodeposition of Manganese and Molybdenum Mixed Oxide Thin Films and Their Charge Storage Properties, Langmuir, 21 (2005) 5907-5913.

[30] K. Rajendra Prasad, N. Miura, Electrochemically synthesized MnO2-based mixed oxides for high performance redox supercapacitors, Electrochem. Commun. 6 (2004) 1004-1008.

[31] H. Kim, B.N. Popov, Synthesis and Characterization of MnO[sub 2]-Based Mixed Oxides as Supercapacitors, J. Electrochem Soc. 150 (2003) D56.

[32] T.C. Liu, W.G. Pell, B.E. Conway, Stages in the development of thick cobalt oxide films exhibiting reversible redox behavior and pseudocapacitance, Electochim. Acta 44 (1999) 28292842.

[33] S. Venkat, J.W. Weidner, Capacitance studies of cobalt oxide films formed via electrochemical precipitation, J. Power Sources, 108 (2002) 15-20.

[34] P.K. Sharma, G.J. Moore, F. Zhang, Z. Peter, M.S. Whittingham, Electrical Properties of the Layered Manganese Dioxides MxMn1-yCoyO2, M = Na, K, Electrochem. Solid-State Lett. 2 (1999) 494-496. 
[35] J.-K. Chang, Y.-L. Chen, W.-T. Tsai, Effect of heat treatment on material characteristics and pseudo-capacitive properties of manganese oxide prepared by anodic deposition, J. Power Sources, 135 (2004) 344-353.

[36] J.-K. Chang, M.-T. Lee, C.-H. Huang, W.-T. Tsai, Physicochemical properties and electrochemical behavior of binary manganese-cobalt oxide electrodes for supercapacitor applications, Mater. Chem. Phys. 108 (2008) 124-131.

[37] O.A. Vargas, A. Caballero, L. Hernán, J. Morales, Improved capacitive properties of layered manganese dioxide grown as nanowires, J. Power Sources, 196 (2011) 3350-3354.

[38] Y.K. Hsu, Y.C. Chen, Y.G. Lin, L.C. Chen, K.H. Chen, Reversible phase transformation of MnO2 nanosheets in an electrochemical capacitor investigated by in situ Raman spectroscopy, Chem. Commun. 47 (2011) 1252-1254.

[39] X. Zhang, P. Yu, H. Zhang, D. Zhang, X. Sun, Y. Ma, Rapid hydrothermal synthesis of hierarchical nanostructures assembled from ultrathin birnessite-type $\mathrm{MnO} 2$ nanosheets for supercapacitor applications, Electrochim. Acta 89 (2013) 523-529.

[40] N. Xu, Z.-H. Liu, X. Ma, S. Qiao, J. Yuan, Controlled synthesis and characterization of layered manganese oxide nanostructures with different morphologies, J. Nanopart. Res. 11 (2008) 1107-1115.

[41] W. Changzheng, X. Yi, W. Dong, Y. Jun, L. Tanwei, Selected-Control Hydrothermal Synthesis of v-MnO2 3D Nanostructures, J. Phys. Chem. C, 107 (2003) 13583-13587.

[42] W.N. Li, J. Yuan, X.F. Shen, S. Gomez-Mower, L.P. Xu, S. Sithambaram, M. Aindow, S.L. Suib, Hydrothermal Synthesis of Structure- and Shape-Controlled Manganese Oxide Octahedral Molecular Sieve Nanomaterials, Adv. Fun. Mater. 16 (2006) 1247-1253. 
[43] L.I. Hill, A. Verbaere, D. Guyomard, $\mathrm{MnO} 2(\alpha-, \beta-, \gamma-)$ compounds prepared by hydrothermal-electrochemical synthesis: characterization, morphology, and lithium insertion behavior, J. Power Sources, 119-121 (2003) 226-231.

[44] W. Xun, L. Yadong, Synthesis and Formation Mechanism of Manganese Dioxide Nanowires/Nanorods, Chem. Eur. J. 9 (2003) 300-306.

[45] L. Xingyou, H. Akihiko, F. Takeshi, C. Mingwei, Nanoporous metal/oxide hybrid electrodes for electrochemical supercapacitors, Nat. Nanotech. 6 (2011) 232-236.

[46] T. Brousse, M. Toupin, R. Dugas, L. Athouël, O. Crosnier, D. Bélanger, Crystalline $\mathrm{MnO}_{2}$ as Possible Alternatives to Amorphous Compounds in Electrochemical Supercapacitors, J. of Electrochem. Soc. 153 (2006) A2171.

[47] O. Ghodbane, J.L. Pascal, F. Favier, Microstructural effects on charge-storage properties in MnO2-based electrochemical supercapacitors, ACS Appl. Mat. Interfaces, 1 (2009) 1130-1139.

[48] M. Nakayama, K. Suzuki, K. Okamura, R. Inoue, L. Athouël, O. Crosnier, T. Brousse, Doping of Cobalt into Multilayered Manganese Oxide for Improved Pseudocapacitive Properties, J. Electrochem. Soc. 157 (2010) A1067.

[49] A. Di Fabio, A. Giorgi, M. Mastragostino, F. Soavi, Carbon-Poly(3-methylthiophene) Hybrid Supercapacitors, J. Electrochem. Soc. 148 (2001) A845.

[50] J. Shen, A. Liu, Y. Tu, H. Wang, R. Jiang, J. Ouyang, Y. Chen, Asymmetric deposition of manganese oxide in single walled carbon nanotube films as electrodes for flexible high frequency response electrochemical capacitors, Electrochim. Acta 78 (2012) 122-132. 
Table 1. EIS fit parameters of $\mathrm{MnO}_{2}$ and $\mathrm{Co}-\mathrm{MnO}_{2}$ electrodes

\begin{tabular}{lccccc}
\hline Fit parameters & $\mathrm{MnO}_{2}$ & $1 \% \mathrm{Co}-\mathrm{MnO}_{2}$ & $2 \% \mathrm{Co}-\mathrm{MnO}_{2}$ & $5 \% \mathrm{Co}-\mathrm{MnO}_{2}$ & $10 \% \mathrm{Co}-\mathrm{MnO}_{2}$ \\
\hline $\mathrm{Rs}(\Omega)$ & 3.67 & 3.1 & 2.5 & 2.7 & 3.7 \\
$\mathrm{R}_{\mathrm{ct}}(\Omega)$ & 11.19 & 5.25 & 4.94 & 3.99 & 4.05 \\
$\mathrm{C}_{\mathrm{dl}}(\mathrm{mF})$ & 0.33 & 0.23 & 0.73 & 1.06 & 1.28 \\
$\mathrm{Z}_{\mathrm{w}}(\Omega)$ & 1.57 & 1.24 & 2.46 & 2.68 & 4.75 \\
$\mathrm{R}_{\mathrm{L}}(\mathrm{k} \Omega)$ & 2.02 & 1.55 & 0.53 & 0.45 & 1.87 \\
$\mathrm{C}_{\mathrm{p}}\left(\mathrm{Fg}^{-1}\right)$ & 124 & 170 & 227 & 294 & 180 \\
\hline
\end{tabular}

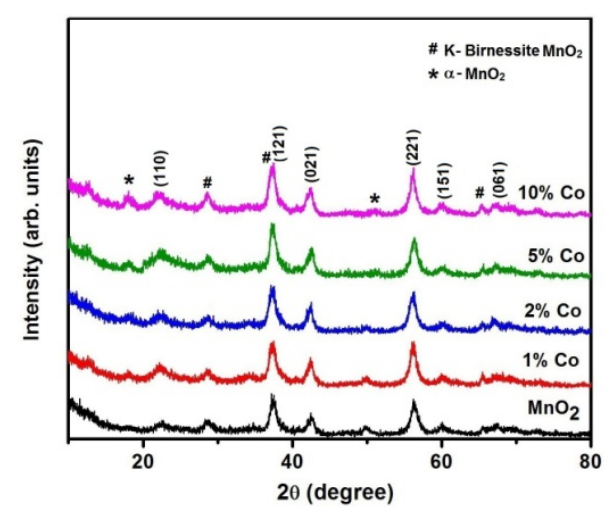

Fig. $1 \mathrm{X}$-ray diffraction pattern of $\mathrm{MnO}_{2}$ and Co- $\mathrm{MnO}_{2}$ electrodes.

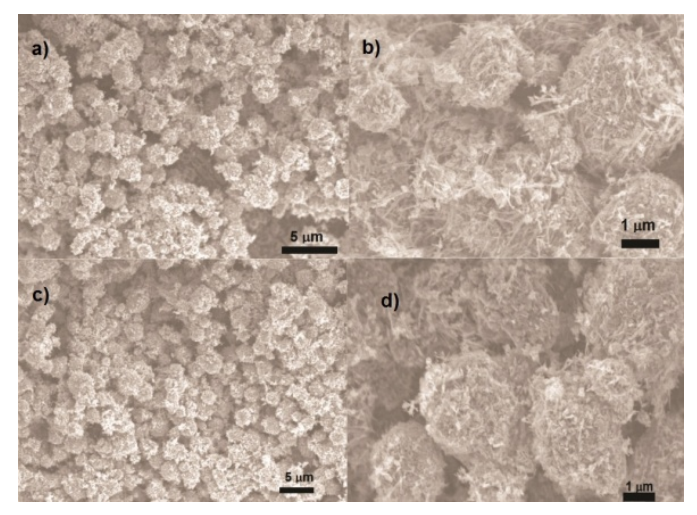

Fig. 2 FESEM image of a, b) bare $\mathrm{MnO}_{2}$ and c, d) $5 \%$ Co- $\mathrm{MnO}_{2}$ nanocomposites. 


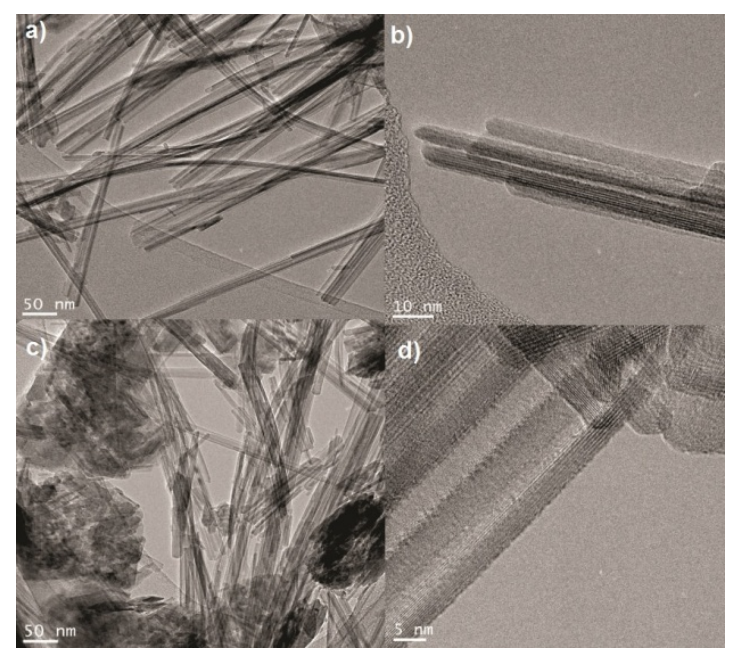

Fig. 3 TEM image of a, b) bare $\mathrm{MnO}_{2}$ and c, d) $5 \%$ Co- $\mathrm{MnO}_{2}$ nanocomposites.

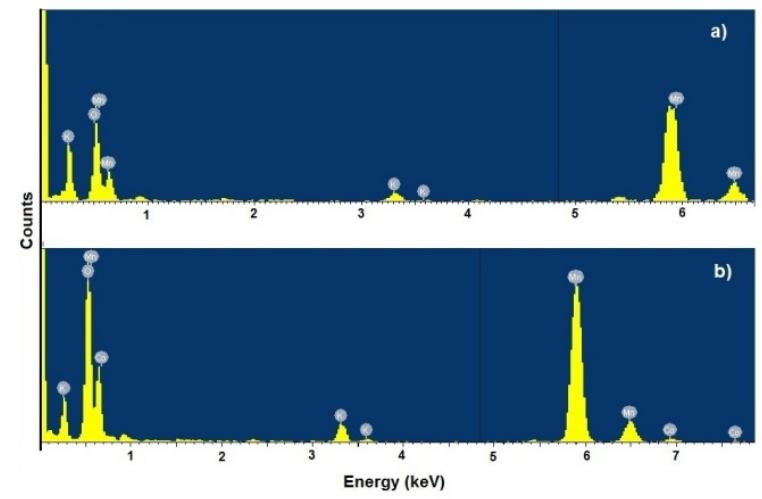

Fig. 4 EDAX spectrum of a) bare $\mathrm{MnO}_{2}$ and b) $5 \%$ Co- $\mathrm{MnO}_{2}$ nanocomposites.

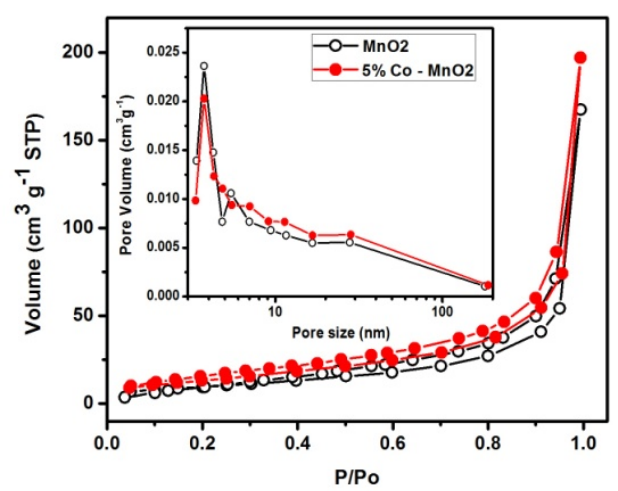

Fig. $5 \mathrm{~N}_{2}$ absorption/desorption isotherms and inset pore size distribution of the bare $\mathrm{MnO}_{2}$ (open circle) and 5\% Co- $\mathrm{MnO}_{2}$ (bold circle) samples. 


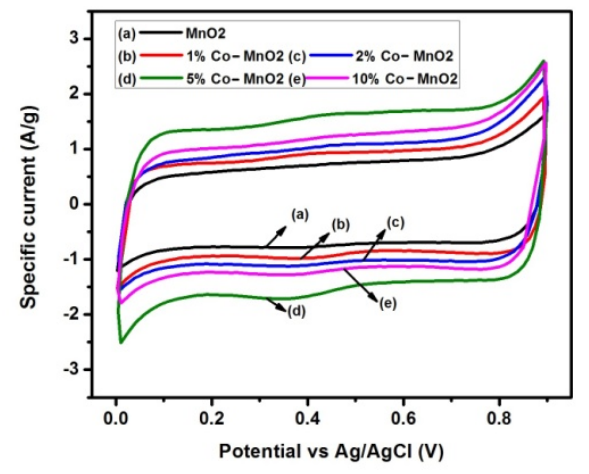

Fig. 6 Cyclic Voltammograms of bare $\mathrm{MnO}_{2}, 1 \%, 2 \%, 5 \%$ and $10 \%$ Co- $\mathrm{MnO}_{2}$ electrodes in $1 \mathrm{M}$ $\mathrm{Na}_{2} \mathrm{SO}_{4}$ electrolyte at $10 \mathrm{mVs}^{-1}$ scan rate.

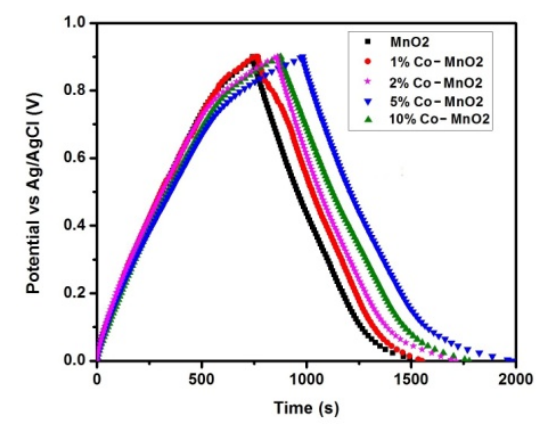

Fig.7 The charge/discharge curve for $\mathrm{MnO}_{2}, 1 \%, 2 \%, 5 \%$ and $10 \%$ Co- $\mathrm{MnO}_{2}$ electrodes at a constant current density of $0.2 \mathrm{Ag}^{-1}$ in $1 \mathrm{M} \mathrm{Na}_{2} \mathrm{SO}_{4}$ electrolyte.
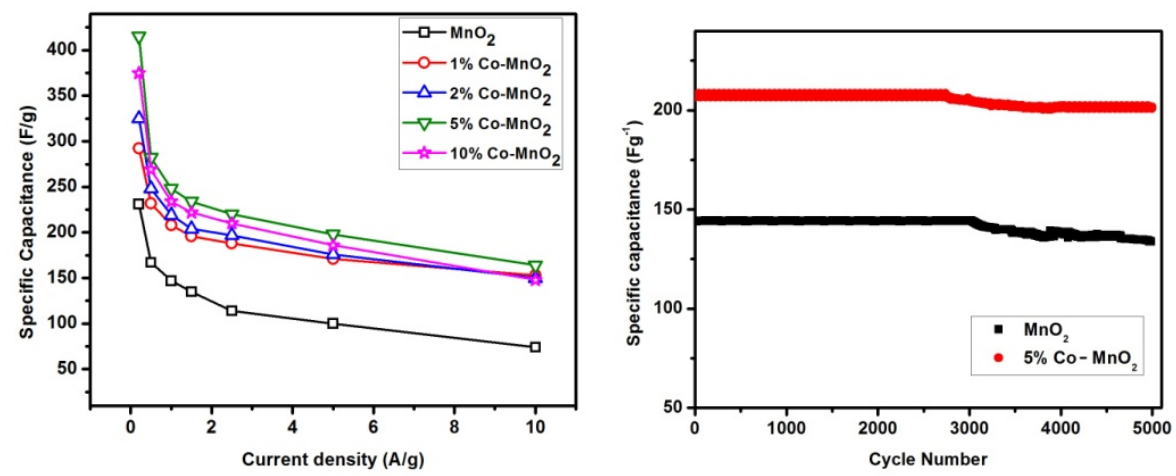

Fig. 8 a) Variation of specific capacitance with discharge current density for bare $\mathrm{MnO}_{2}$ and Co$\mathrm{MnO}_{2}$ electrodes and b) Cycle life of the $\mathrm{MnO}_{2}$ and $5 \%$ Co- $\mathrm{MnO}_{2}$ electrode at a constant current density of $5 \mathrm{Ag}^{-1}$. 

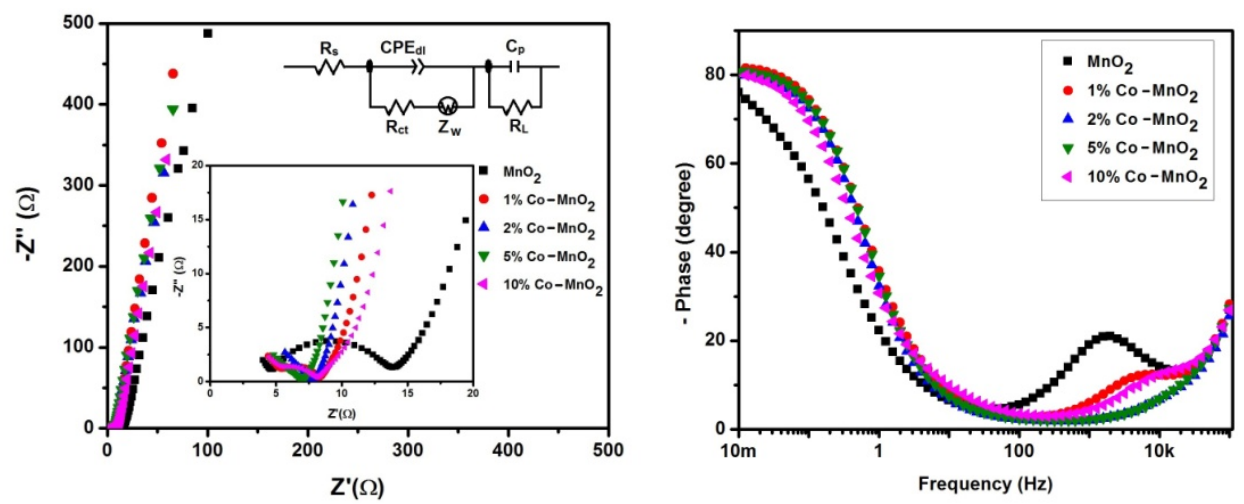

Fig. 9 a) Nyquist plots for the $\mathrm{MnO}_{2}$ and $\mathrm{Co}-\mathrm{MnO}_{2}$ electrodes, inset shows the equivalent circuit of fit and b) the Bode plots of $\mathrm{MnO}_{2}$ and Co- $\mathrm{MnO}_{2}$ electrodes . 